\title{
What Do Definites Do That Indefinites Definitely Don't?*
}

\author{
Daniel Büring (UCLA) \\ buring@humnet.ucla.edu
}

\section{Introducing the Problem}

This paper investigates how (in)definiteness in word order; more specifically, how it in the ordering of objects in the Mittelfeld of German double-object constructions. As a starting point I take what I'll call the Indefinite Puzzle.

\subsection{The Indefinite Puzzle}

According to Lenerz (1977), dative-accusative (henceforth dat-acc) order in German is unmarked, which means it can occur with all F(ocus)-patterns. Accusative-dative (acc$d a t$ ) order is marked, re by the fact that it can only occur with selected F-patterns. The reader is referred to Lenerz (1977) or Büring (forthcoming) for the full range of data, but a summary of the facts is given in the following table:

\begin{tabular}{|l|c|c|c|c|}
\hline F-marked: & Dat only & Acc only & both & neither \\
\hline dative-accusative & ok & ok & ok & ok \\
\hline accusative-dative & ok & $*$ & $*$ & $*$ \\
\hline
\end{tabular}

Of particular interest here is the optionality in word oder in the first column of the table (only the dative object is F-marked). The following example illustrates this case (I use capitals to indicate pitch accents, both primary and, where relevant, secondary; where more than one accent is indicated within a sentence, the last one will be the primary, or nuclear, accent; focus patterns are elicited by lead-in questions or other lead-in material):

(1) Wem hast du das Buch gegeben?

'Who did you give the book (to)?'

a. Ich habe dem SCHÜler das Buch gegeben.

$I$ have the-DAT student the book given

b. Ich habe das Buch dem SCHÜler gegeben.

I have the book the-DAT student given.

'I gave the book to the student'

It is important to be clear about the sense of the term 'unmarked' used here: (1b) as an answer to the question given is no less acceptable to native speakers than (1a). The reason Lenerz calls acc-dat order 'marked' relates to the grammar of German as a whole: Dat-acc order (the 'unmarked' one) can appear without any other factors such as

* I'd like to thank Summer Kern, Line Mikkelsen and an anonymous reviewer for their useful and detailed comments on a draft version of this article. 
focus/background order recommending it; acc-dat order on the other hand, is only possible where some other factor favors it. I will therefore speak of dat-acc order as the lexico-syntactically unmarked order.

Paraphrasing Lenerz in this way, the optionality in (1) arises because both forms have something to recommend them: (1a) displays (lexico-syntactically) unmarked datacc order, while (1b) displays unmarked background-focus (as opposed to focusbackground) order. The reader can verify that this 'tie' between lexico-syntactic unmarkedness and focus-structural unmarkedness is not found in any of the other columns in the table above.

In Büring (forthcoming) I propose to derive these facts, among others, from a general theory of prosodic phrasing, focus and word order; this account will be summarized in section 2. My aim in this paper is to address a set of additional facts only noted in passing in that earlier work, a representative datum for which is (2):

(2) Wem hast du ein Buch gegeben?

'Who did you give a book (to)?'

a. Ich habe dem SCHÜler ein Buch gegeben.

$I$ have the-DAT student a book given

b. Ich habe ein Buch dem SCHÜler gegeben.

I have a book the-DAT student given.

'I gave a book to the student'

Notice the contrast between (2), which doesn't allow for acc-dat order, and the earlier (1), which did. The only difference between the two is that the accusative object in (2) is indefinite, where its counterpart in (1) is definite. The immediate diagnosis for this case, it would seem, is that definite NPs want to precede indefinite NPs even more than focused NPs want to follow unfocused ones. The question I will explore in this paper is: Just what is the status of this tendency in grammatical theory? Three possible explanations will be discussed:

- A purely morphosyntactic constraint: 'Definites precede Indefinites'

- A pragmatic conspiracy: Definites are often discourse-old, indefinites are often discourse-new. New material is focused, old material is not, so indefinites will follow definites because foci follow the non-foci (the background).

- A semantic constraint: Indefinites have no quantificational force of their own, so they need to be in a position that is mapped onto the nuclear scope (NS) of a tripartite quantificational structure (if they are to be interpreted existentially); this mapping is in turn regulated by structural constraints which locate material that is to be mapped onto the NS towards the end of the sentence.

Each of these factors and its relevance for object ordering in word order languages such as German has been proposed somewhere in the literature, either without regard to the others, or as an alternative to one of them. My conclusion in this paper will be that indeed all of these factors seem to be active in German, and that none of them is sufficient to explain the data alone. Accordingly, I will provide a way of integrating them in a unified model, using ranked violable constraints. 


\subsection{Morphosyntax Isn't All}

Let me start by arguing against a purely morphosyntactic account, which would strive to explain the contrast between (1) and (2) by postulating a general prohibition against the order indefinite-definite; note that $(2 \mathrm{~b})$, but not $(1 \mathrm{~b})$ would violate this prohibition. In terms of ranked constraints, this solution would postulate the following ranking: ${ }^{1}$

definite before indefinite $\gg$ dative before accusative $\ll \gg$ background before focus

I submit, however, that such a constraint cannot be the solution to the Indefinite Puzzle. Observe with Lenerz (1977) that the same asymmetry between definite and indefinite accusatives shows up if the focused dative itself is indefinite: An unfocused accusative can precede it, but only if the accusative is definite:

(4) Wem hast du das/ein Buch gegeben?

Who did you give the/a book (to)?

a. Ich habe einem SCHÜler das Buch gegeben.

I have a-DAT student the book given

b. Ich habe einem SCHÜler ein Buch gegeben.

I have a-DAT student a book given

c. Ich habe das Buch einem SCHÜler gegeben.

$I$ have the book a-DAT student given

d. *Ich habe ein Buch einem SCHÜler gegeben.

I have a book a-DAT student given

This example aptly provides two arguments against using a general prohibition against indefinite-definite order. First, (4a) demonstrates that indefinites can precede definites given dative-accusative order. This should be impossible, if (3) were correct. Second, (4d) shows that an unfocused indefinite accusative cannot precede a focused indefinite dative, just as little as it could a focused definite dative in (2b). Clearly, this cannot be captured by any constraint that alludes to the definite-indefinite contrast. I conclude that reference to the morphological definite-indefinite distinction - even though active in German, as we will see - will not help us to solve the Indefinite Puzzle.

\subsection{The Relation Between Definiteness/Indefiniteness and Background/ Focus}

In this subsection I will brie outline the connection between (in)definiteness and focusing, and then show why the Indefinite Puzzle cannot be solved by it either. ${ }^{2}$ The connection I am talking about can be illustrated by the following reasoning:

\footnotetext{
I I presuppose familiarity with OT-type analyses and the standard notational devices used therein.

2 I assume here the kind of theory of focus advocated in Selkirk (1984), Selkirk (1995), and Schwarzschild (1999), among others; see von Stechow (1981), von Stechow (1989), von Stechow (1991), and the references therein for a discussion of the semantics of focus.
} 
(5) a. Definites and indefinites differ with respect to the familiarity of their referents:

i. Indefinites introduce new discourse referents.

ii. Definites refer to old discourse referents.

b. New material must be in the focus of a sentence, old material constitutes the background.

c. Therefore, indefinites are always focused, while definites are always in the background.

d. To the extent that focused elements follow background elements (say, for prosodic reasons), it follows that indefinites follow definites.

While this reasoning is correct over all and might in fact be held responsible for some of the ordering restrictions on indefinites, it is simply not strict enough to account for the Indefinite Puzzle. The reason is that several steps in the argument are valid for the majority of cases, but not all. Let me make caveats about three of them here:

Definites refer to old discourse referents. While true in tendency, there are numerous exceptions to this, as critics of the so-called 'familiarity theory of definites' continue to point out, among them unique definites such as the sun, the number 2 or the first man on the moon and dependent definites as in John lost his keys/the keys to his house.

New material must be in the focus of a sentence, old material constitutes the background. I know of no reason to doubt the first half of this claim (under a reasonably liberal construal of what can pass as non-new, at least), but the second half is clearly too strong. Consider a question-answer pair such as Who did John's mother praise? - She praised JOHN., a variation on Schwarzschild's (1999:145) ex. (11). Here John in the answer is discourse old (i.e. the word John has just been spoken in the question) and refers to an old discourse referent (the same John that was mentioned in the question), yet it is focused. For an enlightening discussion of such cases, sometimes — though I believe misleadingly — called 'contrastive foci' (e.g. Rochemont 1986), see Schwarzschild (1999).

Therefore, indefinites are always focused, while definites are always in the background. I have just discussed two cases in which this equation breaks down for definites, namely definites that introduce a new discourse referent (the keys to his house) and definites that are in focus despite being discourse-old. On top of that, indefinites, even if introducing a new discourse referent, can be in the background if their lexical material has been previously mentioned, as in the following English examples, where a rose is not focused (it is unaccented despite being in the sentencefinal position):

(6) (After Dirk had conveyed to Amber how much he likes roses,) she FInally BOUGHT him a rose.

The indefinite roses in the lead-in doesn't introduce a discourse referent, so the use of an indefinite in the answer is possible; but it makes the phrase a rose given, so that $a$ rose doesn't need to be focused in the answer. Thus, while it is likely to be true that 
indefinites, in declaratives at least, always introduce new discourse referents, it is clearly false that they always have to be in focus. ${ }^{3}$

As far as the Indefinite Puzzle is concerned, all three of the above caveats are potentially relevant here. First, the dative object dem Schüler in (1) and (2), although definite, is in focus. We interpret it either as truly discourse new (in which case it must be construed as a dependent definite or as discourse-unique in some other way); or, more likely, we accommodate a prior discourse in which its discourse referent has been introduced, in which case it is an instance of a given definite which is nonetheless focused. Second, the indefinite accusative object ein Buch, even though presumably introducing a discourse referent, is not focused, because its descriptive content is given in the context (here: the question). Thus the link between definiteness/indefiniteness and background/focus breaks down in these examples, yet the fact remains that the indefinite can't precede the definite. I conclude that the Indefinite Puzzle cannot be solved by recourse to the focus/background distinction alone. ${ }^{4}$

\subsection{A Semantic Mapping Effect}

We have seen that neither a morphosyntactic 'definites precede indefinites' constraint, nor recourse to background/focus structure can explain the Indefinite Puzzle. I believe, though, that something along the lines explored in the previous section is true: While they don't need to be in focus, indefinites do need to be with a certain semantic domain, namely in a place where they can get existential closure, to borrow a term from Heim (1982). As noted there, indefinites do not have quantificational force of their own; rather, their quantificational force is determined by their environment. If semantically an indefinite gets interpreted within the restrictive clause of a quantifier, it inherits the quantificational force of that quantifier. Only if the indefinite is interpreted within the nuclear scope of a quantifier does it receive an existential interpretation. Kratzer (1995) and Diesing (1992), elaborating on this idea of Heim's, have proposed that even sentences without overt quantificational elements are mapped onto a tripartite quantificational structure involving a nuclear scope and a restrictive clause. I'd like to explore the idea that indefinite accusatives such as ein Buch in (2) cannot precede the dative because they have to be in a syntactic position which will be mapped onto the nuclear scope, rather than the restrictive clause, of a quantificational structure, and that position is following the dative.

Evidence for this general line of reasoning comes from sentences such as (7):

3 I am less certain that indefinites in questions never introduce discourse referents, given examples like Is there an ATM around here? - It's right behind you. Note that, unlike in an example like Did you see a big black cat? - It went that way. it seems implausible to call an ATM 'specific' (even in scare quotes) in this example.

4 An alternative that comes to mind is to count unstressed indefinites as 'focused' in some abstract sense and then insist that acc-dat order is impossible with an unstressed (yet allegedly focused) indefinite accusative object, given that the resulting structure will always violate the "background precedes focus' constraint to at least the same degree as the dat-acc structure. Such a strategy is of course impossible to adopt in an approach like mine, which tries to reduce effects of focus to effects of stressing (unless I want to claim that indefinites are also always 'stressed' in some abstract sense . . . ). The approach I present below, however, is as close as I can get to this strategy by claiming that indefinites do need to be within a certain domain, and that that domain wants to coincide with the focus. 
Wem würdest Du ein Buch schenken?

'Who would you give a book?'

a. Ich würde ein Buch einem SCHÜler schenken.

I would a book a-DAT student give

b. Ich würde ein Buch dem SCHÜler F schenken.

I would a book the-DAT student give

'I'd give a book to a/the student'

The surprising thing about the two answers in (7) is that the unfocused indefinite ein Buch precedes the focused dative ein/dem Schuler. Why, then, are (7a) and (7b) possible, but (4d) and (2b) are not? The answer, I believe, is that the indefinites in (7) are not interpreted existential, but generic. The sentences can be paraphrased as:

\section{typically, if I had an $\mathrm{x}$ which is a book, I'd give $x$ to a/the student}

As opposed to that, the sentences in (2) involve an existential indefinite; their paraphrase is something like:

there is an $\mathrm{x}$ which is a book, and I gave $x$ to a/the student

It seems that indefinite accusatives can precede a dative only if they are to receive a generic interpretation. If they are to be interpreted existentially, they have to follow the dative, because that is the domain which will be interpreted as part of the nuclear scope, and hence receive existential force.

The reason (2b) and (4d) are unacceptable is thus a complex one: Their overall form (indicative mood, perfective tense) makes it pragmatically hard to understand them as generic statements. Their generic reading would be something as far-fetched as 'for typical $x$, if $x$ was a book, I gave $x$ to a/the student' (people like myself, who have trained themselves in getting farfetched readings do actually get this reading for (2b)/ (4d)). And their word order, in particular the acc-dat order, makes it impossible to give the indefinite accusative ein Buch the pragmatically plausible existential interpretation.

The question obviously is: Just what constitutes the syntactic counterpart to the semantic nuclear scope? In our particular case, why can an accusative following a dative get mapped onto the nuclear scope, whereas an accusative preceding a dative cannot? Different authors have given different answers to these questions: According to Kratzer (1995) and Diesing (1992), it is the VP that is mapped onto the nuclear scope; an accusative preceding a dative would have to be generic if we were to assume that accdat order can only arise through VP-adjunction of the accusative. Krifka (1995), on the other hand, argues that the focus is mapped onto the nuclear scope, a position slightly modified by Eckardt (1996), who postulates an abstract category Fl-focus, which does not necessarily coincide with the focus marked by accenting (Eckardt's $F 2$-focus), to be the structural counterpart to the nuclear scope; under this view, the acc-dat order must entail that the accusative is outside of the (F1-) focus.

My proposal is perhaps most similar to that in Eckardt (1996). It crucially differs from it, however, in that I assume that the relevant unit for the syntax-semantics mapping is in fact a prosodic one, the accent domain to be introduced in the next section. The gist of the proposal is that having an existential indefinite accusative in front of the focus cannot yield a structure which both constitutes an improvement over 
the dat-acc order in terms of focus structure, and at the same time allows for the indefinite to be mapped onto the nuclear scope. Such an acc-dat order is thus only possible if either the accusative is a generic indefinite, as in (7), or a definite NP, which doesn't care whether it is in the nuclear scope or not, as in (1). To demonstrate how this accounts for the Indefinite Puzzle, I'll first have to introduce the prosody based account of focus-related word order variation proposed in Büring (forthcoming), which will be done in section 2 . Following that, I will present and motivate a prosody-based account of existential closure in section 3. With all that in place I can then give an account of how (in)definiteness, focus and the existential/generic dichotomy in prosodic phrasing, accenting and word order in German double object constructions in section 4, where, among other things, a solution to the Indefinite Puzzle will be proposed.

\section{Variation in Object Order -A Prosody Based Account}

The cornerstone of the analysis I outline in this section (essentially that proposed in more detail in Büring forthcoming) is that word order is determined by at least two kinds of constraints: Constraints that refer to the lexico-syntactic properties of a constituent, such as its case, its animacy or its (morphological) definiteness; and constraints that refer to the properties of a constituent in an utterance type, such as whether it is focus or background, and what kind of semantic interpretation it receives. Languages that give more weight to the former, such as English, are traditionally called fixed word order languages (since the word order seems invariable if viewed from the morphosyntactic point of view, even though it is of course quite regarding the question of where, say, a focus can occur), while those that give more weight to the latter, such as the Slavic languages, are often called free word order languages (though their word order is rather fixed if viewed from a focus/background perspective).

A second hypothesis I explore here is that focus- and interpretation-related constraints do not directly in linear order, but only indirectly, via their effect on prosodic phrasing. Prosodic phrasing will in turn be related to word order by markedness constraints.

In German, optionality between two word orders arises if the two kinds of constraints favor different linear orders; strict word order, on the other hand, is the result of agreement between them. A helpful way to think about this is that German has two operative grammars, one lexico-syntactically driven, one prosodically driven (and hence heavily in by such things as focus). For each grammars, there is an optimal form; we thus have a lexico-syntactic winner and a, possibly distinct, prosodic winner. Formally, I will implement this via a constraint tie.

\subsection{Lexico-Syntactic Factors}

In many approaches, ditransitive verbs are taken to lexically specify an 'unmarked' order amongst their objects. In this paper, I follow an alternative line of analysis, according to which the unmarked order is determined by the interplay of three factors: Animacy, Case, and Definiteness. I adopt the specific analysis in Müller (1998), according to which these are encoded in the form the three constraints in (10), ordered as shown in (11): 
(10) Lexicosyntactic Constraints:
a. ANIMACY
Animate NPs precede inanimate NPs.
b. DATIVE
Datives precede accusatives.
c. DEFINITENESS
Definites precede indefinites

As these factors are not my primary concern in this paper, I refer the interested reader to Müller (1998) for a discussion and justification of them. For the purpose of my presentation I will almost exclusively consider cases involving animate datives and inanimate accusatives. That way, I can simply talk about the lexico-syntactically optimal candidate (the one with dat-acc order) and ignore cases where animacy and case push in different directions, as well as whatever subordinate effects morphological definiteness might have. In the tableaux to follow I will summarize these three constraints as $\mathrm{d}-\mathrm{a}$, reminiscent of 'dative precedes accusative', but this is no more than a convenient abbreviatory convention.

$$
\begin{aligned}
& \text { abbreviatory convention: } \\
& \mathrm{D}-\mathrm{A}=_{\text {def }} \text { ANIMACY }>>\text { DATIVE }>>\text { DEFINITENESS }
\end{aligned}
$$

I should mention that this system, as developed by Müller, does not predict forms to be ungrammatical, but merely degraded. That is, ceteris paribus, an inanimate dative preceding an animate accusative will be degraded compard to an animate accusative preceding an inanimate dative (since ANIMACY outranks DATIVE), but not unacceptable; and even an inanimate accusative preceding an animate dative will be deteriorated, but not hopeless. These graded judgements, whatever their actual implementation, can be imported into the system here, but they will be immaterial for most all of the examples considered.

\subsection{Focus}

Let us now turn to those constraints that regard non-lexical properties of constituents, beginning with focus. Why do foci tend to follow non-foci? I suggest that the answer involves two steps: First, German (just like English) has an unmarked prosodic structure in which more or less each phrasal constituent of a clause corresponds to an accent domain (AD), the rightmost one of which becomes the head of the intonational phrase (iP), and thereby most prominent among the ADs. ${ }^{5}$ The unmarked structure thus looks like (13):

5 The prosodic correlate of an accent domain is the presence of phrase level stress (marking its head), which in turn is a necessary condition for association with a pitch accent. Quite presumably, ADs are identical to the phonological phrases of Selkirk (1984) or Truckenbrodt (1999) and show other prosodic correlates such as boundary tones, final lengthening, breaks etc. More investigation of this issue is needed, though. The prosodic correlate of the intonational phrase is a final boundary tone and, most prominently, an obligatory pitch accent on its head, the nuclear accent. 


$$
\begin{array}{lcc}
\left(\begin{array}{c}
\mathrm{X} \\
\mathrm{XP}
\end{array}\right)_{\mathrm{AD}}(\mathrm{YP})_{\mathrm{AD}}(\mathrm{ZP})_{\mathrm{AD}} &
\end{array}
$$

Second, German (like many languages) adheres to a constraint that requires foci to be prosodically prominent, called FocusProminence or FP for short (Truckenbrodt 1995; 1999). For example, if an AD contains an F-marked constitutent, it wants to achieve prominence by becoming the head of the iP. Thus in (13), ZP could legitimately contain a focus, since it is the head of iP and thereby most prominent. Alternatively, YP and ZP could both contain foci, in which case YP violates FP (it is not the head of iP), but not fatally, since any alternative phrasing (e.g. one in which YP, rather than XP, is the head of iP) would violate FP as well (e.g. because XP isn't the head of iP) plus possibly additional constraints. ${ }^{6}$

What cannot happen is that $\mathrm{YP}$, but not $\mathrm{ZP}$ is a focus, because this involves an avoidable violation of FP. To understand this we have to look at the constraints in more detail, though:

Accent Domain Formation To regulate accent domain formation we import the following two constraints, more or less directly from Truckenbrodt (1995):

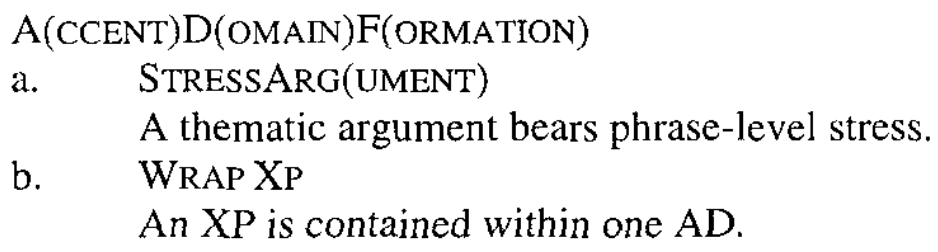

STRESSARG prevents two non-overlapping NPs (or any two non-overlapping constitutents) from being mapped into one big $\mathrm{AD}$, because that way only one of them would receive phrase-level stress (qua being the head of that $\mathrm{AD}$ ). To see this we have to pay attention to secondary accents, as in the following example, where meiner Mutter. 'my mother', must bear a (secondary) pitch accent, which in turn is indicative of phrase-level stress, i.e. the presence of an $\mathrm{AD}:^{7}$

Warum warst du auf der Post?

why were you at the post office

a. Ich will meiner MUtter eine POSTkarte schicken.

I want my mother a postcard send

b. $\quad$ \#Ich will meiner Mutter eine POSTkarte schicken.

6 The reader might wonder if YP and ZP cannot simply form one AD which then becomes the head of iP, thereby avoiding any violation of FP, as in (XP)AD (YP ZP)AD, where boldface indicates maximal prominence. The answer here is that this phrasing violates the formal version of FP at the AD level, because the prosodic word corresponding to YP fails to become the head of AD, despite containing a focus. And it's turtles all the way down: If a phrase contains two or more F-marks with neither dominating the other, a FP violation will inevitably occur at some level.

7 My account predicts that XPs preceding the head of iP will almost always form an AD, due to STRESS-ARG; (15) illustrates this with a case in which my mother is also focused. It is less obvious that unfocused XPs necessarily form an AD; they certainly do not need to bear a pitch accent, even though they can. As noted above, the concept of an AD thus doesn't have a necessary prosodic correlate, but only entails the possibility of a pitch accent. 
The following tableau derives this: ${ }^{8}$

\begin{tabular}{|l|c|}
\hline i: $\quad$ XP YP & STRESSARG \\
\hline a. $\rightarrow(\mathrm{XP})_{\mathrm{AD}}(\mathrm{YP})_{\mathrm{AD}}$ & \\
\hline b. $\quad(\mathrm{XP} Y \mathrm{YP})_{\mathrm{AD}}$ & $* !$ \\
\hline
\end{tabular}

WRAPXP, on the other hand, prevents XPs from being unduely fractured. For example, a verbal predicate will be in the same $\mathrm{AD}$ as an adjacent argument, given that separating them would violate WRAPXP for XP=VP. This is the effect Jacobs (1992) calls integration, cf. also von Stechow and Uhmann (1986):

(16) Gudrun möchte Astronautin werden, und Peter will ...

Gudrun wants astronaut become, and Peter wants

a. ... DAMPFschiffe bauen.

steam boats build

b. \# ... DAMPFschiffe BAUen.

c. \#... Dampfschiffe BAUen.

'Gudrun wants to become an astronout, and Peter wants to build steam boats'

\begin{tabular}{|c|c|c|}
\hline \multirow{2}{*}{\multicolumn{3}{|c|}{ i: $\quad \mathrm{NP}_{\text {object }} \mathrm{V}$}} \\
\hline & & \\
\hline b. $\quad(\mathrm{NP})_{\mathrm{AD}}(\mathrm{V})_{\mathrm{AD}}$ & & $* !$ \\
\hline c. $\quad(\mathrm{np} \mathrm{V})_{\mathrm{AD}}$ & $* !$ & \\
\hline
\end{tabular}

Notice, too, that in an argument-head complex, the argument, rather than the head, will be the head of the AD, hence prominent (indicated by (NP $v$ ), as in (a), as opposed to $(n p \mathrm{~V})$, as in (c), in the tableaux). This follows from STRESSARG as well, given that NP, but not $\mathrm{V}$ is an argument. The overall effect of these constraints is that predicates form an $\mathrm{AD}$ with their adjacent argument, while all other constituents form their own $\mathrm{AD}$ (see, once again, Truckenbrodt 1995).

Nuclear Stress and Accent: As mentioned above, ADs aren't the highest level of prosodic structure. Simple sentences like the ones I am concerned with in this paper are mapped onto an intonational phrase (iP). The only relevant constraint in connection with the present investigation is that the head of $\mathrm{iP}$ is right-peripheral in German (again, just like in English). This accounts for the fact that in a sentences with more than one pitch accent, such as (15) above, the final one is most prominent, cf. (18) (where $\mathrm{x}$ marks $\mathrm{AD}$-level stress and $\mathrm{X}$ marks iP-level stress):

(17) IpHeadRight (IpHR)

An $\mathrm{iP}$ and the $\mathrm{AD}$ that is its head are right-aligned.
a.

$\begin{array}{lcc}\mathrm{x} & \mathrm{X} & )_{\mathrm{iP}} \\ (\text { meiner } & \text { MUtter })_{A D}(\text { eine POSTkarte schreiben })_{A D}\end{array}$

8 Here and throughout, the a. and b. numbers in the tableaux refer to the example sentence immediately preceding the tableau. Where there is more than one candidate structure for a single example sentence, I'll use a., a.', a." etc. 


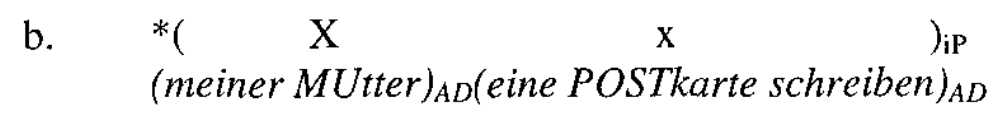

In the following tableaux I use boldface for the constituent that is the head of iP (I continue to use upper case letters for the head of an AD):

\begin{tabular}{|l|l|l|l|}
\hline i: NP NP V & IPHR & STRESSARG & WRAPXP \\
\hline a. $\rightarrow$ (NP)AD (NP v) AD & & & \\
\hline b. (NP)AD(NP v) AD & $* !$ & & \\
\hline
\end{tabular}

Focus Prominence: The final constraint I borrow from Truckenbrodt (1995) is FOCUSPROMINENCE:

\section{FOCUSPROMINENCE (FP) \\ Focus is most prominent. ${ }^{9}$}

Space does not allow me to discuss the effects of FP with a wider variety of F-patterns, cf. Büring (forthcoming), but let me brie illustrate three basic cases: Focus on a rightmost XP, focus on two XPs, and focus on a penultimate XP.

If the rightmost phrase in a clause is F-marked, the standard pattern (13) will arise, in compliance with all constraints discussed:

\begin{tabular}{|l|c:c:c|c|}
\hline $\mathrm{i}: \mathrm{XP}_{\mathrm{YP}}$ & IPHR & FP & STRESSARG & WRAPXP \\
\hline$\rightarrow(\mathrm{XP})_{\mathrm{AD}}(\mathbf{Y P})_{\mathrm{AD}}$ & & & & \\
\hline$(\mathrm{Xp} \mathbf{Y P})_{\mathrm{AD}}$ & & & $* !$ & \\
\hline$(\mathbf{X P} \text { yp })_{\mathrm{AD}}$ & & $* !$ & $*$ & \\
\hline
\end{tabular}

The same prosodic structure emerges if two XPs are focused. One of them will inevitably violate FP, but this will be unavoidable: In (a) below, (the AD containing) $\mathrm{XP}$ fails to become the head of iP, in (b) (the prosodic word containing) it fails to become the head of $\mathrm{AD}$, and in (c) the same happens to YP. Which structure is chosen thus depends on STRESSARG alone:

\begin{tabular}{|l|c|c|c|c|}
\hline i: $\quad \mathrm{XP}_{\mathrm{F}} \mathrm{YP}_{\mathrm{F}}$ & $\mathrm{IPHR}$ & $\mathrm{FP}$ & STRESSARG & WRAPXP \\
\hline a. $\rightarrow(\mathrm{XP})_{\mathrm{AD}}(\mathbf{Y P})_{\mathrm{AD}}$ & & $*$ & & \\
\hline b. $\quad(\mathrm{xp} \mathbf{Y P})_{\mathrm{AD}}$ & & $*$ & $* !$ & \\
\hline c. $\quad(\mathbf{X P} \text { yp })_{\mathrm{AD}}$ & & $*$ & $* !$ & \\
\hline
\end{tabular}

The final and by far most interesting case arises if a non-final YP is focused. What we observe is that the non-final YP receives the nuclear accent, and that no secondary accents can be on the XP(s) following YP:

(20) Wem hast du eine Postkarte geschrieben? - Ich habe...

Who have you a postcard written? -I have

9 As said, the most prominent prosodic constituent within a larger constituent is defined as the head of that constituent. The formal version of $\mathrm{Fp}$ is: If $\alpha$ is a prosodic constituent at level $\mathrm{n}$ which contains a syntactic node that is F-marked, $\alpha$ is the head of the prosodic category at level $n+1$ that contains $\alpha$. 

a. $\quad .$. meiner MUtter eine Postkarte geschrieben.
my mother a postcard written
b. \# . . . meiner MUtter eine POSTkarte geschrieben.
c. \# . . meiner Mutter eine POSTkarte geschrieben.

I interpret this to imply that we have one AD that spans from the left edge of the focus to the end of the sentence/iP. This, obviously, is an imperfect prosodic structure. Why is it chosen? Note that in a case like this, STRESSARG, FP and IPHR are in con If perfect ADs are formed, IPHR and FP cannot simultaneously be met. Either the final AD becomes the head of iP and thereby most prominent, as in (b), which violates FP (given that the focus sits in the penultimate $\mathrm{AD}$ ); or the non-final $\mathrm{AD}$ (the one containing the focus) becomes the head of iP, meeting FP but violating IPHR, as in (b'). Alternatively, ADF could be sacrificed, as in (a), with the benefit of reconciling IPHR and FP (because now the focus is within the rightmost AD). Evidently, this is what happens in German. The conclusion is that STRESSARG must be outranked by IPHR and FP: ${ }^{10}$

\begin{tabular}{|l|c:c|c:c|}
\hline i: $\quad \mathrm{XP}_{\mathrm{F}} \mathrm{YP}$ & IPHR & FP & STRESSARG & WRAPXP \\
\hline a. $\rightarrow(\mathbf{X P} y \mathrm{yp})_{\mathrm{AD}}$ & & & $*$ & \\
\hline b. $(\mathrm{XP})_{\mathrm{AD}}(\mathbf{Y P})_{\mathrm{AD}}$ & & $* !$ & & \\
\hline b. $(\mathbf{X P})_{\mathrm{AD}}(\mathrm{YP})_{\mathrm{AD}}$ & $* !$ & & & \\
\hline c. $\quad(\mathrm{xp} \mathbf{Y P})_{\mathrm{AD}}$ & & $* !$ & $*$ & \\
\hline
\end{tabular}

This 'destructuring' effect of non-final foci has been observed for various languages, among them German in Uhmann (1991:237ff), where a similar rationale for it is offered, and Japanese (see, among others, Nagahara 1994, Uechi 1998, and the references therein). The essentials of the analysis adopted here are due to Truckenbrodt (1995:ch.5), where it is set in the context of a broader typology of focus-alignment effects. The fact that non-final foci lead to marked prosodic structures is central to the explanation of focus-related word order variation in Büring (forthcoming) to be presented in the next subsection; it has also been adopted for the analysis of focusrelated word order variation in Spanish in Gutiérrez-Bravo (1999).

In the remainder of this paper I will summarize the constraints WRAPXP and STRESSARG as ADF (reminiscent of accent domain formation) in the tableaux, which is violated whenever an $\mathrm{AD}$ contains less than an XP, or more than an XP plus its predicate.

(21) abbreviatory convention:

$\mathrm{ADF}={ }_{\text {def }}$ STRESSARG, WRAPXP

\subsection{Focus Related Word Order Variation}

We just saw that focus on a non-rightmost XP leads to a prosodic structure with an 'extra-large' $\mathrm{AD}$, namely one that extends from the beginning of the focused XP to the end of iP (here: the sentence). Only in this way can the focus be maximally prominent and be in the rightmost AD in iP. Notably, this extra-large AD could be avoided while

10 I assume for the sake of this exposition that WRAPXP is subordinated, too, though this hasn't been demonstrated. 
respecting all other constraints if XP and YP could be freely reordered (the use of $\{\ldots\}$ in the input specification of the following tableaux means that the input is unspecified for word order):

\begin{tabular}{|ll|c:c|c|}
\hline i: & $\left\{\mathrm{XP}_{\mathrm{F}} \mathrm{YP}\right\}$ & $\mathrm{IPHR}$ & $\mathrm{FP}$ & $\mathrm{ADF}$ \\
\hline a. & $(\mathbf{X P} \text { yp })_{\mathrm{AD}}$ & & & $* !$ \\
\hline b. $(\mathrm{XP})_{\mathrm{AD}}(\mathbf{Y P})_{\mathrm{AD}}$ & & $* !$ & \\
\hline b. $\quad(\mathbf{X P})_{\mathrm{AD}}(\mathrm{YP})_{\mathrm{AD}}$ & $* !$ & & \\
\hline d. $\rightarrow(\mathrm{XP})_{\mathrm{AD}}(\mathbf{Y P})$ & & & \\
\hline
\end{tabular}

This idea provides the basis of an account of focus related word order variation: If an $\mathrm{XP}$ is unfocused, having it in front of a focused one will provide for a perfect prosodic structure which is nonetheless in keeping with FP.

This isn't quite German, however, because while German allows non-canonical word order in such cases, it doesn't require it. To implement this, we go back to the lexicosyntactic constraints discussed in subsection 2.1 above and summarized there as d-a ('dative before accusative'). These constraints will be used to counter-balance the effects of the prosodic constraints, assuming a ranking as in (22), where prosodic constraints and lexico-syntactic constraints are tied: ${ }^{11}$

$$
\text { IPHR, FP }>\text { ADF }<<>\text { D-A }
$$

The effect of this tie is that both the prosodically optimal candidate and the lexicosyntactic candidate are grammatical, in other words: optionality (where the two are different, that is). To demonstrate the effects of this, let us go back to our initial example (1), repeated here:

(23) Wem hast du das Buch gegeben?

'Who did you give the book (to)?'

a. Ich habe dem SCHÜler das Buch gegeben.

I have the-DAT student the book given

b. Ich habe das Buch dem SCHÜler gegeben.

I have the book the-DAT student given.

'I gave the book to the student'

\begin{tabular}{|l|l|l|l|}
\hline i: $\left\{\right.$ dat $_{\mathrm{F}}$ acc $\}$ & IPHR & FP & ADF \\
\hline a. $\rightarrow(\text { DAT } \text { acc })_{\mathrm{AD}}$ & & & $*$ \\
\hline a.' $(\mathrm{DAT})_{\mathrm{AD}}(\mathbf{A C C})_{\mathrm{AD}}$ & & $* !$ & \\
\hline a." $(\mathbf{D A T})_{\mathrm{AD}}(\mathrm{ACC})_{\mathrm{AD}}$ & $* !$ & & \\
\hline b. $\rightarrow(\mathrm{ACC})_{\mathrm{AD}}(\mathbf{D A T})_{\mathrm{AD}}$ & & & \\
\hline
\end{tabular}

As said earlier, we can think of such a tie as encoding two different grammars. Thus the tableau above abbreviates the two tableaux below, which present the resolution of the tie into the 'prosodic grammar' and the 'lexico-syntactic grammar', respectively:

11 The alert reader will have noticed that what is tied here are not two constraints but rather two subhierarchies of constraints, which, it must be admitted, constitutes a significant deviation from what is normally considered an ordering or ranking. 


\begin{tabular}{|ll|l:l|l|l|}
\hline i: $\quad\left\{\right.$ dat $_{\mathrm{F}}$ acc & IPHR & FP & ADF & D-A \\
\hline a. $(\mathbf{D A T} \text { acc })_{\mathrm{AD}}$ & & & $* !$ & \\
\hline a. $\quad(\mathrm{DAT})_{\mathrm{AD}}(\mathbf{A C C})_{\mathrm{AD}}$ & & $* !$ & & \\
\hline a." $\quad(\mathbf{D A T})_{\mathrm{AD}}(\mathrm{ACC})_{\mathrm{AD}}$ & $* !$ & & & \\
\hline b. $\rightarrow(\mathrm{ACC})_{\mathrm{AD}}(\mathbf{D A T})_{\mathrm{AD}}$ & & & & $*$ \\
\hline
\end{tabular}

\begin{tabular}{|l|l|l|l|l|}
\hline i: $\quad\left\{\right.$ dat $_{\mathrm{F}}$ acc $\}$ & IPHR & FP & ADF & D-A \\
\hline a. $\rightarrow(\mathbf{D A T} \text { acc })_{\mathrm{AD}}$ & & & & $*$ \\
\hline a. $\quad(\mathrm{DAT})_{\mathrm{AD}}(\mathbf{A C C})_{\mathrm{AD}}$ & & $* !$ & & \\
\hline a." $\quad(\mathbf{D A T})_{\mathrm{AD}}(\mathrm{ACC})_{\mathrm{AD}}$ & $* !$ & & & \\
\hline b. (ACC) $)_{\mathrm{AD}}(\mathbf{D A T})_{\mathrm{AD}}$ & & & $* !$ & \\
\hline
\end{tabular}

We thus have implemented the optional non-canonical word order. And we derive that optionality emerges only if the lexico-syntactically unmarked order yields an imperfect prosodic structure, compare (1)/(23) to (24), which corresponds to the second column in the very first table on page 1 :

(24) Was hast du dem Schüler gegeben?

What have you the student given
a. Ich habe dem Schuiler das BUCH gegeben.
$I$ have the student the book given
b. \#Ich habe das BUCH dem Schüler gegeben.

Here, since the lexico-syntactically unmarked dat-acc order also allows for a perfect prosodic phrasing, no word order variation is possible:

\begin{tabular}{|l|l|l|ll|}
\hline i: $\quad$ dat $_{\mathrm{F}}$ acc $\}$ & IPHR & FP & ADF & D-A \\
\hline a. $\rightarrow(\mathrm{DAT})_{\mathrm{AD}}(\mathbf{A C C})_{\mathrm{AD}}$ & & & & \\
\hline a. ${ }^{\prime}(\text { dat } \mathbf{A C C})_{\mathrm{AD}}$ & & & $* !$ & \\
\hline b. (ACC dat $)_{\mathrm{AD}}$ & & & $* !$ & $* !$ \\
\hline b. $\quad(\mathrm{ACC})_{\mathrm{AD}}(\mathbf{D A T})_{\mathrm{AD}}$ & & $* !$ & & $*$ \\
\hline
\end{tabular}

Our next task is to show why acc-dat $t_{\mathrm{F}}$ order is impossible if the accusative is indefinite. As shown above, this cannot just be due to a lexico-syntactic constraint that wants indefinites to follow definites. I argued that in order to understand what kind of constraint is operative here, we have to realize that the incrimated order is possible, but only if the indefinite is generic. It is thus an effect of being non-generic, rather than being indefinite per se that we observe here. Let us therefore examine the generic/existential contrast more closely.

\section{Generic and Existential Indefinites}

As announced at the end of section 1, I want to explore the idea that the domain of existential closure, the nuclear scope, corresponds to a prosodic domain. As we saw in the previous section, a sentence consists of a linear sequence of accent domains $\left(\mathrm{AD}_{1}\right)$ $\left(\mathrm{AD}_{2}\right) \ldots\left(\mathrm{AD}_{\mathrm{n}}\right)$. With respect to the mapping onto the tripartite structure, I propose that, 
going from left to right, the mapping onto the nuclear scope can start at any accent domain $\mathrm{AD}_{\mathrm{m}}$, and then continues until the end of the sentence. As an additional restriction, the nuclear scope must be left-aligned with an $\mathrm{AD}$ which contains a focus.

Consider the abstract structure in (25), which represents a sentence with four accent domains, the last two of which contain foci. I will use : $\exists$ to mark where the mapping onto the nuclear scope starts (=the domain of existential closure). According to the above idea, (25a) and (b) represent well-formed mappings, but (25c) and (d) do not, because in the latter, accent domains which do not contain a focus are mapped onto the nuclear scope:

$$
\begin{array}{ll}
(\mathrm{AD} 1)(\mathrm{AD} 2)\left(\mathrm{AD} 3_{\mathrm{F}}\right)\left(\mathrm{AD}_{\mathrm{F}}\right) \\
\text { a. } & (\mathrm{AD} 1)(\mathrm{AD} 2)\left(\mathrm{AD} 3_{\mathrm{F}}\right): \exists\left(\mathrm{AD}_{\mathrm{F}}\right) \\
\text { b. } & (\mathrm{AD} 1)(\mathrm{AD} 2): \exists\left(\mathrm{AD} 3_{\mathrm{F}}\right)\left(\mathrm{AD} 4_{\mathrm{F}}\right) \\
\text { c. } & *: \exists(\mathrm{AD} 1)(\mathrm{AD} 2)\left(\mathrm{AD} 3_{\mathrm{F}}\right)\left(\mathrm{AD} 4_{\mathrm{F}}\right) \\
\text { d. } & *(\mathrm{AD} 1): \exists(\mathrm{AD} 2)\left(\mathrm{AD} 3_{\mathrm{F}}\right)\left(\mathrm{AD} 4_{\mathrm{F}}\right)
\end{array}
$$

I will implement this as in (26):

\section{ALIGN NUCLEAR SCOPE (ANS)}

The nuclear scope consists of complete accent domains, all of which contain focus.

On a speculative note, it is perhaps justified to think of (26) as an iconicity constraint, whose objective it is to mark a domain of content, the nuclear scope, by aligning it with a domain of form, ADs containing pitch accents. Be that as it may, indefinites are specified as either existential or generic in the input, a specification which cannot be overriden, due to an undominated constraint Faith $(\exists / G)$ :

$\operatorname{FAITH}(\exists / \mathrm{G})(\mathrm{F} \exists \mathrm{G})$

An indefinite specified as existential (generic) in the input is interpreted existentially (generically)

In the representations that follow I will use $: \exists$ as above in the candidates, and subscript indefinites with $\exists$ or $G$ in the candidates and the input. Viewed this way, (26) is an alignment constraint (because it seeks to align the nuclear scope with a focus), and (27) is an input/output faithfulness constraint (because it prohibits change of $\exists$ to $G$ and vice versa). ${ }^{12}$

(26), in tandem with (27), will have two distinct effects: Existential indefinites will need to be in an $\mathrm{AD}$ that contains a focus (so that $: \exists$ can precede that $\mathrm{AD}$ ), while generic

12 Eventually it might be advantageous, however, to view $\exists / \mathrm{G}$ and $; \exists$ as notational shorthands for aspects of the interpretation, not parts of the syntactic or prosodic representation. On this view, a candidate will consist of an interpretation alongside with prosodic and perhaps syntactic structure(s), and (26) as well as (27) are correspondence rules that hold between the different representations that make up a candidate (cf. Jackendoff (1997)). Inspired by this perspective I refrain from giving a constraint that prohibits existential NPs preceding the : -boundary; there can be no existential indefinites outside of the nuclear scope, because being existential and being in the nuclear scope are one and the same thing. All there can be is an indefinite that was specified as existential in the input, but winds up generic in the output. 
indefinites need to be in an $\mathrm{AD}$ that precedes at least one $\mathrm{AD}$ containing a focus (so that $: \exists$ can follow the indefinite while still preceding a focus-containing AD). To motivate this, it is instructive to study the generic/existential contrast under circumstances where it does not interact with the other object-ordering constraints. Consider (28): ${ }^{13}$

$$
\begin{aligned}
& \text { Wenn man in die USA einreisen will, muss man... } \\
& \text { if one into the US enter wants, must one } \\
& \text { a. } \quad . \text { VORstrafen ANgeben. } \\
& \text { previous convictions list } \\
& \text { b. ... VORstrafen angeben. }
\end{aligned}
$$

'If you want to enter the US, you have to list previous convictions.'

These two sentences differ only in their prosodic shape; in (28a) we find two ADs, as witnessed by two accents (the latter of which is the most prominent one, due to IPHR). It expresses the generic reading of this sentence, which happens to be true: If you travel to the US and you have previous convictions, you have to list them. In (28b) we find integration, i.e. object and verb form one $\mathrm{AD}$ whose head is the object, in accordance with the principles discussed above. It expresses an existential reading, 'if you want to enter the US, there must be previous convictions for you to list', which is of course false.

Let us start by deriving (28b), which is run-of-the-mill. The prosodic constraints in

\begin{tabular}{|c|c|c|c|c|c|c|}
\hline $\mathrm{i}: \quad \mathrm{ACC}_{\mathrm{F}, \exists} \mathrm{V}_{\mathrm{F}}$ & IPHR & $\mathrm{FP}$ & $\mathrm{F} \exists \mathrm{G}$ & ANS & $A D F$ & $D-A$ \\
\hline a. $\quad: \exists\left(\mathrm{ACC}_{\exists}\right)(\mathrm{V})$ & & $*$ & & & $* !$ & \\
\hline b. $\rightarrow: \exists\left(\mathrm{ACC}_{\exists} \mathrm{v}\right)$ & & $*$ & & & & \\
\hline
\end{tabular}
ADF favor the integrated structure. F $\mathrm{g}$ and ANS aren't involved here, since the sentence doesn't contain a generic NP, and since the indefinite is itself part of the focus (which is VP or some higher constituent) (I will henceforth leave out the AD subscript in the

\begin{tabular}{|c|c|c|c|c|c|c|}
\hline $\mathrm{i}: \quad \mathrm{ACC}_{\mathrm{F}, \exists} \mathrm{V}_{\mathrm{F}}$ & IPHR & FP & $\mathrm{F} \exists \mathrm{G}$ & ANS & ADF & D-A \\
\hline a. $\rightarrow\left(\mathrm{ACC}_{\mathrm{G}}\right): \exists(\mathbf{V})$ & & $*$ & & & $*$ & \\
\hline a. $\quad: \exists\left(A C C_{\exists}\right)(V)$ & & * & *! & & * & \\
\hline b. $: \exists\left(\mathrm{ACC}_{\exists} \mathrm{v}\right)$ & & * & $* !$ & & & \\
\hline b.' $\quad\left(\mathbf{A C C}_{\mathrm{G}}: \exists \mathrm{v}\right)$ & & * & & $* !$ & & \\
\hline
\end{tabular}
candidates for perspicuity; note that all parentheses in the candites represent ADs):

What about (28a)? This structure will be the optimal realization for a generic NP, provided that we rank $\mathrm{F} \exists \mathrm{g}$ and ANS higher than ADF:

13 Note that most of the examples I present in this sub-section involve focused generic indefinites. Notice the temptation to reduce the in of the generic/existential contrast to focus or familiarity along the following lines: Generic indefinites are prime candidates for staying unfocused, because they can be repeated in a discourse, in order to refer to the genus or kind they name, again and again, whereas an existential indefinite cannot be repeated in order to refer to the same individual again (that's were you use a definite instead). Repeated things (generic indefinites or definites) are unfocused, so we derive that generic indefinites patterns with definites.

The cases of focused generics warn us not to give in to that temptation: Focused generics behave different from focused existentials, just as unfocused generics behave different from unfocused cxistentials, as I will show later on. 
We have thus captured the connection between semantics and prosody in (28). A generic NP will force separation into two ADs, against prosodic constraints (an observation made e.g. by Krifka (1999, sec.1.4.7)). An existential NP will integrate (as NPs generally prefer to do). Each of the resulting prosodic patterns is the optimal candidate for their respective NP-type. There is a one-to-one correlation between prosodic structure and reading.

This correlation, however, is not always observed, because crucially, ANs itself is not inviolable. Notice that formation of an object-only $\mathrm{AD}$ necessitates formation of a verbonly-AD. Since iP is right-headed, the verbal AD will bear the main prominence. This is fine in (28a), since the $\mathrm{V}$ is focus. It violates FP since the accusative, too, is focus but not most prominent within iP; but one violation of FP is unavoidable and thus not fatal. The alternative structure (28b) violates FP as well (this time on behalf of $\mathrm{V}$ ), but looses out on Ans. This picture will change if $\mathrm{V}$ is not focused:

Stimmt es, daß man sämtliche Knöllchen angeben muss?- Das nicht, aber Is correct it that one all parking tickets list must? - That not, but man muss...

one must

a. \#... VORstrafen ANgeben.

b. ...VORstrafen angeben.

'Do you really have to list all your parking tickets? - Not quite, but you have to list previous convictions'

The former winning candidate, (29a), is unacceptable here. This is because it violates FP in making the non-focused verb angeben, rather than the focused NP Vorstrafen prominent in iP. We predict the correct form (29b) if we rank ANS lower than F $\exists$ :

\begin{tabular}{|ll|l:c:c|c|cc|}
\hline i: $\quad \mathrm{ACC}_{\mathrm{F}, \exists} \mathrm{V}_{\mathrm{F}}$ & $\mathrm{IPHR}$ & $\mathrm{FP}$ & $\mathrm{F} \exists \mathrm{G}$ & $\mathrm{ANS}$ & $\mathrm{ADF}$ & $\mathrm{D}-\mathrm{A}$ \\
\hline a. $\quad\left(\mathrm{ACC}_{\mathrm{G}}\right): \exists(\mathbf{V})$ & & $* !$ & & & $*$ & \\
\hline b. $\rightarrow\left(\mathbf{A C C}_{\mathrm{G}}: \exists \mathrm{V}\right)$ & & & & $*$ & & \\
\hline
\end{tabular}

Note incidentally that $(29 \mathrm{~b})$ is optimal for the same F-pattern with an existential indefinite object, too - as in (28b) (the first tableau). The generic-existential contrast is thus prosodically neutralized in these narrow focus cases.

It is interesting to note that the generic indefinites in (28a) and (29b) bear stress, in the latter case even main stress. Data like these have been noted in Büring (1996:4, ex.(6)), and Eckardt (1996:60, ex (31), attributed to I.Kohlhof, p.c.), where it is also noticed that they pose serious problems for focus-based accounts of the generic/existential contrast such as Krifka (1995) and Eckardt (1996). It should also be noted that the present analysis is not committed to any phrase-structural difference between the sentences with different types of indefinites, as proposed in de Hoop (1992) and Diesing (1992). A thorough comparison to these theories is beyond the scope of the present investigation, however.

It is quite conceivable that a similar constraint-pattern holds for English. Since English is VO, the difference between $(\mathrm{V})_{\mathrm{AD}}(\mathrm{O})_{\mathrm{AD}}$ and $(\mathrm{V} \mathrm{O})_{\mathrm{AD}}$ does not result in a shift of the nuclear accent, as it does in the German cases in (28), and is thus less easily detectable. It has been observed, though, that subject-integration, j.e. forming a single 
$\mathrm{AD}$ out of a subject and an intransitive verb, interacts with genericity. Consider the following contrast from Halliday (1967), reported in Rooth (1996:273):
a. SHOES must be worn.
b. DOGS must be CARried.

Rooth comments:

"If you bring along no dog at all, you obey the second regulation, but if you bring no shoes at all, you violate the first. If you carry one dog and bring another on a leash, you violate the second regulation; but if you wear one pair of shoes and carry another pair in a shopping bag, you obey the first." (Rooth 1996:2)

It should be easy to see that the English subject-verb pattern is entirely parallel to the object-verb patterns observed in the German examples in (28):

$(\text { ARGUMENT predicate) })_{\mathrm{AD}}$

$$
(\text { ARGUMENT })_{A D}(\text { PREDICATE })_{\mathrm{AD}}
$$

satisfies ADF, is compatible with ANS if argument is existential, but violates it if argument is generic

violates $\mathrm{ADF}$, but satisfies ANS if argument is generic

In fact, the same relative ranking of ANS and ADF would account for these English facts, too, even though there doubtlessly are more complications. That this parallelism might not be coincidental is also suggested by the fact that the same 'neutralization' observed in (29) above occurs in English:

(31) Hey, you've got to carry your cat here. That's what the regulations say! - No dude,...

a. DOGS must be carried (, CATS can go on a LEASH).

b. \#DOGS must be CARried

The same reasoning applies here: The generic indefinite dogs in (31) wants to form its own $\mathrm{AD}$, on behalf of ANS, as the one in $(30 \mathrm{~b})$. But then the rest of the sentence must form an $\mathrm{AD}$, too, which would be the rightmost one and therefore receive main prominence; and that violates the higher constraint FP. The result is unacceptable as seen in (31b). Therefore, the sentence will be squeezed into one big AD as in (31a).

Summing up, we have seen that generic indefinites, unlike existential ones, like to form an $\mathrm{AD}$ of their own. I have proposed to capture this by a constraint that regards the mapping between prosodic structure and interpretation which governs the 'cut-off point' for the domain of existential closure, the nuclear scope. This constraint will not only affect generic indefinites (by forcing them to precede that point), but also existential indefinites (by forcing them to follow it). With this constraint, we finally have all the pieces in place to return to the placement of indefinites in double object constructions, and the Indefinite Puzzle in particular. 


\section{Indefinites In Double Object Constructions}

\subsection{Existential Indefinites in the Background: Solving the Indefinite Puzzle}

We are now in a position to solve the Indefinite Puzzle: Why can't an unfocused indefinite precede a focused dative, where unfocused definite accusatives can?

(32) Wem hast du das/ein Buch gegeben?

who have you the/a book given

a. Ich habe das Buch dem SCHÜler gegeben

I have the book the student given

b. *Ich habe ein Buch dem SCHÜler gegeben

I have a book the student given

Recall that an unfocused accusative precedes the dative to improve prosodic structure:

$\left(\text { DAT }_{\mathrm{F}} \text { acc } \mathrm{v}\right)_{\mathrm{AD}} \quad$ (lexico-syntactically unmarked)

$(\mathrm{ACC})_{\mathrm{AD}}\left(\mathbf{D A T}_{\mathrm{F}} \mathrm{v}\right)_{\mathrm{AD}}$ (prosodically unmarked)

To understand the peculiar behavior of indefinite accusatives, or existential indefinite accusatives, to be precise, note that the $a c c$-dat-structure provides no basis for properly inserting the : $\exists$-boundary in that case. Inserting it in front of the accusative would violate ANS (because the $\mathrm{AD}$ following it doesn't contain a focus), inserting it after the accusative would leave the indefinite accusative without existential force, violating F9g. The following tableau illustrates this:

\begin{tabular}{|c|c|c|c|c|c|c|c|}
\hline i: & $\left\{\mathrm{ACC}_{\exists} \mathrm{DAT}_{\mathrm{F}} \mathrm{V}\right\}$ & IPHR & FP & $\mathrm{F} \exists \mathrm{G}$ & ANS & $\mathrm{ADF}$ & $\mathrm{D}-\mathrm{A}$ \\
\hline (2) & a. $\rightarrow: \exists\left(\right.$ DAT acc $\left._{\exists} v\right)$ & & & & & $*$ & \\
\hline (32) & b. $\quad: \exists\left(\mathrm{ACC}_{\exists}\right)$ (DAT v) & & & & $* !$ & & $*$ \\
\hline & b. $\quad\left(\right.$ ACC $\left._{\mathrm{G}}\right): \exists$ (DAT v) & & & $* !$ & & & $*$ \\
\hline & b." $: \exists\left(\operatorname{acc}_{\exists}\right.$ DAT v) & & & & & $* !$ & $* !$ \\
\hline
\end{tabular}

We have thus solved the Indefinite Puzzle: Using acc-dat order to improve prosody makes it impossible to get an existential reading for the accusative indefinite. And the one candidate which displays acc-dat order and doesn't violate any of the indefiniterelated constraints, (b."), is neither lexico-syntactically nor prosodically unmarked; it violates both ADF and D-A.

Let me review the logic of this account once more. It does not say that an existential indefinite generally has to follow the focus; nor does it say that an existential indefinite accusative cannot occur with acc-dat order. It merely says that an existential indefinite has to form an AD with a focus, and that the order of the indefinite and the focused argument within that $\mathrm{AD}$ will be determined by the lexico-syntactic constraints ANIMACY, DATIVE and DEFINITENESS - alone, which, in the example above, all favor the outcome dat-acc. The remainder of this subsection is devoted to demontrating that this is indeed the correct generalization. 
First, an existential indefinite can precede the focus, if that is what the lexico-syntactic constraints favor. Consider (33), in which we have an unfocused existential dative. DEFINITENESS doesn't apply, and both DATIVE and ANIMACY favor dat-acc order, even though that implies that the unfocused indefinite precedes the focus. And indeed the opposite order in (33b) sounds rather awkward:

(33) Obwohl der Verkauf von Schusswaffen an Minderjährige verboten ist, although the selling of guns to minors prohibited is haben Sie am $28.11 \ldots$

have you on $11 / 28$

a. $\quad \ldots$ einer Minderjährigen eine GASpistole verkauft.

$$
\text { a minor a gas gun sold }
$$

b. \#. . eine GASpistole einer Minderjährigen verkauft.

a gas gun a minor sold

Let us next see what happens if two lexico-syntactic constraints con In (34), ANIMACY isn't relevant, and DATIVE and DEFINITENESS pull in opposite directions. It seems to me that the acc-dat order in (34b) is much better than in the previous example:

(34) (Rainer saw a girl at a party we went to, who he wants to see again. He expects me to know her name, because he saw me introduce her to an Italian looking guy, so he asks:)

Wen hast du einem Italiener vorgestellt?

Who have you an-DAT Italian introduced

a. Ich habe einem Italiener MARION vorgestellt.

$I$ have an-DAT Italian Marion introduced

b. Ich habe MARION einem Italiener vorgestellt.

I have Marion an-DAT Italian introduced

Is this expected under the present account? If DATIVE strictly outranked DEFINITENESS, only (34a) should be grammatical. Recall from subsection 2.1, though, that in the original conception in Müller (1998), the lexico-syntactic constraints derive degradation rather than ungrammaticality. Under that assumption, (34b) would be degraded, but much better than any of the examples to which I gave a \# above. The candidate corresponding to that sentence is marked by $\searrow$ in the tableau below:

\begin{tabular}{|c|c|c|c|c|c|c|}
\hline i: $\quad\left\{\operatorname{ACC}_{\mathrm{F}} \mathrm{DAT}_{\exists} \mathrm{V}\right\}$ & IPHR & FP & $\mathrm{F} \exists \mathrm{G}$ & ANS & $\mathrm{ADF}$ & $\mathrm{D}-\mathrm{A}$ \\
\hline a. $\rightarrow: \exists\left(\right.$ dat $_{\exists} \mathrm{ACC}$ v $)$ & & & & & * & DEF \\
\hline a.' $\quad\left(\mathrm{dat}_{\mathrm{G}}\right): \exists(\mathbf{A C C ~ v )}$ & & & $* !$ & & & DEF \\
\hline a." $\quad: \exists\left(\right.$ dat $\left._{\exists}\right)(\mathbf{A C C}$ v) & & & & $* !$ & & DEF \\
\hline a. $\vee: \exists\left(\mathrm{ACC}_{\mathrm{F}}\right.$ dat $\left._{\exists} \mathrm{v}\right)$ & & & & & * & DAT \\
\hline a.' $\quad: \exists(\mathbf{a c c})\left(\mathbf{D A} \mathbf{T}_{\exists} \mathrm{v}\right)$ & & $* !$ & & & & DAT \\
\hline
\end{tabular}

Note then that (34b) constitutes a (rather rare and curious) case in which a focused accusative can precede an unfocused dative. As just discussed, the present system predicts this, given that accent domain formation isn't relevant in these cases, because 
the non-focused NP is an existential indefinite. ${ }^{14}$ It likewise predicts the sharp contrast to the cases of $a c c_{F}$ dat in which the dative is definite and could thus form its own AD:

(35) Peter weigert sich, mir seine Schwester vorzustellen! Dabei habe ich ...

Peter refuses self me-DAT his sister to introduce! Albeit have I

a. $\quad$.. dem Blödmann MArion vorgestellt. ${ }^{15}$ the-DAT jerk Marion introduced

b. \#. . MArion dem Blödmann vorgestellt. Marion the-DAT jerk introduced

To sum up, an unfocused existential indefinite has to form an AD with the focus. This violates $\mathrm{ADF}$, but it is necessary to meet the higher constraints $\mathrm{F} \exists \mathrm{G}$ and ANs. Therefore, prosodic considerations will not play a role in choosing between acc-dat and dat-acc order; only lexico-syntactic-constraints will. In standard cases as Lenerz' (2), the lexicosyntactic-constraints will unanimously favor dat-acc, accounting for the Indefinite Puzzle. In other cases, like (34), the lexico-syntactic constraints con with each other and a certain degree of word order freedom is predicted.

\subsection{Generic Indefinites}

In this subsection and the next I will look at those cases which are not part of the Indefinite Puzzle, but for which the system developed so far makes predictions. Let us start by checking how the constraints formulated so far account for generic indefinites in double object constructions.

\subsubsection{Generics Accusatives that Obligatorily Precede Datives}

A generic indefinite, unlike the existential one in (2), can precede a focused coargument and thus allow for a perfect prosodic structure, cf. (36a). In fact, this acc-dat order is obligatory here, as (36b) shows:

(36) Bisher haben wir Ladendiebe nicht gemeldet, aber nach der neuen Regelung... so far have we shopliftings not reported but according to the new regulation

a. $\quad \ldots$ müssen wir Ladendiebe dem GeSCHÄFTSführer melden. must we shoplifters the manager report

b. \#. . müssen wir dem GeSCHÄFTSführer Ladendiebe melden. must we the manager shoplifters report

'So far we didn't report shoplifters but according to the new regulations, we have to report shoplifters to the manager'

This behavior is predicted, given that for a generic interpretation to obtain, the indefinite must be in the restrictive clause, i.e. preceding the $: \exists$-boundary. The $: \exists$ in turn must

14 They present serious challenges for both phrase-structure and focus/backgroundstructure based accounts of the generic/existential distinction, though, as well as to accounts which directly relate word order variation to focusing.

15 To see that dem Blödmann, 'the jerk', is not focused in this context, consider a sentence in which its accent would be nuclear, such as a continuation like . . . und trotzdem mag ich den Blödmann (". . and still I like the jerk'); the nuclear accent has to sit on mag, absolutely not on Blödmann. 
precede an $\mathrm{AD}$ containing the focus, which means that the indefinite must precede a focus:

\begin{tabular}{|c|c|c|c|c|c|c|}
\hline i: $\quad \operatorname{ACC}_{G} D_{A A T} V$ & IPHR & FP & $\mathrm{F} \exists \mathrm{G}$ & ANS & ADF & D-A \\
\hline a. $\rightarrow\left(\mathrm{ACC}_{\mathrm{G}}\right):{ }_{\exists}($ DAT v $)$ & & & & & & $*$ \\
\hline b. $\quad\left(\mathrm{DAT} \operatorname{acc}_{\mathrm{G}}: \exists \mathrm{v}\right)$ & & & & $* !$ & $*$ & \\
\hline b.' (DAT) $\left(\mathrm{ACC}_{\mathrm{G}}\right):{ }_{\exists}(\mathrm{V})$ & & $* !$ & & $*$ & $*$ & \\
\hline
\end{tabular}

The exact same pattern obtains if the generic indefinite is itself focused, too:

(37) Bisher haben wir Ladendiebstähle nicht gemeldet, aber ab sofort werden wir ... so far have we shopliftings not reported, but as of now will we

a. $\quad .$. WiederHOlungstäter der PoliZEI meIden.

repeat offenders the police report

b. \#. . . der PoliZEI WiederHOlungstäter melden.

the police repeat offenders report

'So far we didn't report shopliftings, but as of now we will report repeat offenders to the police'

This is again as expected, given that the indefinite needs to get the : $\exists$ between itself and the end of the sentence (recall from the discussion of cases like (25a) above that : doesn't need to precede every AD containing a focus, but merely that it precedes only such ADs). This example also shows that optimization of prosodic structure in (36) was a welcome side-effect, but not the driving force behind the obligatoriness of acc-dat order, for there is a structure for the unacceptable (37b), namely (b.'), whose prosodic structure is perfect, too. But it is ungrammatical, due to the violation of $\mathrm{F} \exists \mathrm{G}$ :

\begin{tabular}{|c|c|c|c|c|c|c|c|}
\hline i: & $\mathrm{ACC}_{\mathrm{G}, \mathrm{F}} \mathrm{DAT}_{\mathrm{F}} \mathrm{V}$ & IPHR & FP & $\mathrm{F} \exists \mathrm{G}$ & ANS & $\mathrm{ADF}$ & D-A \\
\hline a. $\rightarrow$ & $\left(\mathrm{ACC}_{\mathrm{G}}\right):_{\exists}($ DAT v $)$ & & & & & & $*$ \\
\hline b. & $(\mathrm{DAT})\left(\mathbf{A C C} \mathbf{C}_{\mathrm{G}}: \exists \mathrm{v}\right)$ & & & & $* !$ & & \\
\hline & $(\mathrm{DAT}): \exists\left(\mathrm{ACC}_{\exists} \mathrm{v}\right)$ & & & $* !$ & & & \\
\hline & $(\mathrm{DAT})(\mathrm{ACC}): \exists(\mathrm{V})$ & & $* !$ & & * & & \\
\hline
\end{tabular}

\subsubsection{Optional Acc-Dat Order with Generic Indefinites}

In the examples discussed in the previous subsection, there were two constraints that favored acc-dat order; ADF, since the dative was narrow focus and thus should be sentence-final (modulo the verb, that is), and ANS/F $\exists$ G, since the generic accusative must have a prosodic phrase boundary following it (for : 9 to align with), which means it has to precede the focus. Note that the former is a weak motivation, since ADF can be overruled by the lexico-syntactic constraints on one resolution of the tie. It is the latter motivation that is responsible for the obligatoriness of acc-dat order, because ANS and $\mathrm{F} \exists \mathrm{G}$ dominate the lexico-syntactic constraints. The prediction is thus that if we manage to 'switch off' ANS and $\mathrm{F} \exists \mathrm{G}$, we would observe optionality between the two orders again. This predication is borne out: If the generic has a chance to form an $\mathrm{AD}$ on its own while following its co-argument, both word orders are possible: 
(38) Damit eine Seite wie diese funktioniert, ist es wichtig... so that a page like this one functions is it important

a. $\quad .$. dass man verALtete LINKS dem WEBmaster meldet. that one outdated links the web-master reports

b. ... dass man dem WEBmaster verALtete LINKS MELdet. that one the web-master outdated links reports

'For a page like this to work it is important that you report outdated links to the web-master.'

The present account predicts this, given that the generic accusative in (38b) can have the $: \exists$ following it and preceding a focus (namely the verb), unlike in (37b), where the verb is unfocused (see the structure in the tableau below). While this structure violates ADF (the verb doesn't integrate with its adjacent argument), it is optimal under lexicosyntactic considerations. Acc-dat order, on the other hand, allows for optimal prosody at the expense of lexico-syntactic markedness, so candidate (a) is grammatical, too, just as in (36) and (37) above:

\begin{tabular}{|c|c|c|c|c|c|c|}
\hline $\mathrm{i}: \quad \mathrm{ACC}_{\mathrm{G}, \mathrm{F}} \mathrm{DAT}_{\mathrm{F}} \mathrm{V}$ & IPHR & FP & $\mathrm{F} \exists \mathrm{G}$ & ANS & $\overline{\mathrm{ADF}}$ & $\overline{D-A}$ \\
\hline a. $\rightarrow\left(\right.$ ACC $\left._{G}\right):{ }_{\exists}($ DAT v $)$ & & $* *$ & & & & $*$ \\
\hline a.' $\quad\left(\mathrm{ACC}_{\mathrm{G}}\right): 3(\mathrm{DAT})(\mathbf{V})$ & & $* *$ & & & $* !$ & $* !$ \\
\hline b. $\rightarrow(\mathrm{DAT})\left(\mathrm{ACC}_{\mathrm{G}}\right): \exists(\mathrm{V})$ & & $* *$ & & & $*$ & \\
\hline b.' (DAT) $\left(\mathrm{ACC}_{\mathrm{G}}: \exists \mathrm{v}\right)$ & & $* *$ & & $* !$ & & \\
\hline b." (DAT): $:\left(\mathbf{A C C} \mathbf{C}_{\exists} \mathrm{v}\right)$ & & $* *$ & $* !$ & & & \\
\hline
\end{tabular}

In the system developed here, the word order freedom in (38) arises from the same tie known from double object constructions that do not involve generic NPs, namely that between a perfect prosodic structure (generic)(nongeneric verb) and a lexicosyntactically unmarked structure (dative)(accusative)(verb). The prediction, then, is that like in the simple cases, the optionality in word order should disappear if prosody and lexico-syntax favor the same outcome. Again, this seems to be a correct prediction:

Damit eine Seite wie diese funktioniert, ist es wichtig...

so that a page like this one functions is it important

a. ... dass man ERSTbenutzern die NUTzungsrechte erklärt. that one novices-DAT the terms of use explains

b. \#. . dass man die NUTzungsrechte ERSTbenutzern erKLÄRT. that one the terms of use novices-DAT explains

'For a page like this to work it is important that you explain the terms of use to first time users.'

This result follows in the same manner: The optimal structure (39a) meets both ADF and DAT, while the alternative order yields (39b), which violates both:

\begin{tabular}{|l|c|c|c|c|cc|}
\hline i: $\quad \mathrm{ACC}_{\mathrm{F}} \mathrm{DAT}_{\mathrm{F}, \mathrm{G}} \mathrm{V}_{\mathrm{F}}$ & IPHR & $\mathrm{FP}$ & $\mathrm{F} \exists \mathrm{G}$ & ANS & ADF & D-A \\
\hline a. $\rightarrow(\mathrm{DAT}):{ }_{\exists}\left(\mathrm{ACC}_{\exists} \mathrm{V}\right)$ & & $* *$ & & & & \\
\hline b. $(\mathrm{ACC})\left(\mathrm{DAT}_{\mathrm{G}}\right):{ }_{\exists}(\mathbf{V})$ & & $* *$ & & & $* !$ & $* !$ \\
\hline b. ${ }^{\prime} \quad(\mathrm{ACC})\left(\mathrm{DAT}_{\mathrm{G}}:{ }_{\exists} \mathbf{V}\right)$ & & $* *$ & & $* !$ & & $*$ \\
\hline
\end{tabular}




\subsection{Existential Indefinites in Focus}

I close this section with a look at existential indefinites in focus. This is a rather boring endeavor, because these behave just like definites in focus: The reason is that a focused indefinite can always form an $\mathrm{AD}$ without running the risk of violating FP, and : 9 can then precede that $\mathrm{AD}$ in keeping with Ans, and thus guarantee an existential reading. Since a focused accusative wouldn't precede a dative for prosodic reasons, we expect to see focused existential indefinites wherever the lexico-syntactic constraints prefer them to be. The examples below illustrate two such cases. In (40) all lexico-syntacticconstraints favor the dat-acc order, which, accordingly, is the only one possible:

(40) Peter wurde für schuldig befunden, ...

Peterwas for guilty found

a. ... einem KolLEgen / seinem CHEF eine BOMbe geschickt zu haben.

a-DAT colleague/his-DAT boss a bomb send to have

b. \#. . . eine BOMbe einem KolLEgen / seinem CHEF geschickt zu haben.

a bomb a-DAT colleague / his-DAT boss send to have

'Peter was found guilty to have send a colleague / his boss a bomb.'

Example (41) is one of the sort I didn't consider much in this paper; DAT and ANIM conflict (with DEF, presumably irrelevantly, siding with DAT); since ADF is neutral on the issue, the acc-dat order, as preferred by the highest lexico-syntactic constraint Anim, wins:

(41) Die Sache wurde kriminell, als sie... the thing became criminal when they

a. ... einen GeFANgenen dem LÜgendetektortest aussetzen wollten. a-ACC prisoner the-DAT lie detector test expose wanted

b. \#... dem Lügendetektortest einen GeFANgenen aussetzen wollten. the-DAT lie detector test a-ACC prisoner expose wanted

'The whole thing got criminal when they wanted to expose a prisoner to the lie detector test.'

\begin{tabular}{|c|c|c|c|c|c|c|c|}
\hline i: & $\mathrm{ACC}_{\mathrm{F}, 3,+a n} \mathrm{DAT}_{\mathrm{F}, 3,- \text { an }} \mathrm{V}_{\mathrm{F}}$ & IPHR & FP & $\mathrm{F} \exists \mathrm{G}$ & ANS & $\mathrm{ADF}$ & $\mathrm{D}-\mathrm{A}$ \\
\hline a. $\rightarrow$ & $: \exists\left(\mathrm{ACC}_{\exists,+ \text { an }}\right)\left(\mathbf{D A T}_{\exists,- \text { an }} \mathrm{v}\right)$ & & $* *$ & & & & DAT \\
\hline $\mathrm{b}$. & $:_{\exists}\left(\mathbf{D A T}_{\exists,-\mathrm{an}}\right)\left(\mathrm{ACC}_{\exists,+ \text { an }} \mathrm{v}\right)$ & & $* *$ & & & & ANIM! \\
\hline
\end{tabular}

We see, thus, that the definite/indefinite distinction is void if the pertinent NP is in focus.

\section{Conclusion}

This paper explored in what ways the defininte/indefinite distinction in word order in the German Mittelfeld. I have found three distinct factors to be relevant, the morphosyntax, focussing, and interpretation. The analysis developed models each of them and shows how they interact. Particular attention was devoted to the interpretation-related constraints that regulate the formal realization of the 
generic/existential distinction. I took as my starting point a simple generalization about the phrasing-behavior of generic vs. existential indefinites, which was motivated outside the realm of double object constructions; I then demonstrated how that very generalization, when combined with a theory of stress-related word order variation such as that of Büring (forthcoming), yields a wide range of correct predications about double object constructions.

I have tried to control for the various parameters such as focus/givenness, animacy, case, definiteness etc. as scrupulously as I could, and I believe the picture presented in this paper to have a fine-grainedness and accuracy that exceeds that of previous studies. Nonetheless, I could only present here a fraction of the different combinations of parameters that the theory makes predictions for (about 430, I believe), and I won't pretend to have been able to reliably test all the others in the privacy of my office. Also, while I've been careful to steer clear of some potentially relevant factors such as scopal dependencies or more complex F-patterns within the argument NPs, I have no doubt that there are others which make themselves felt in the examples discussed in this paper and lead me to wrong interpretations of my findings (I can't shake off the feeling, for example, that some of the more complex double object constructions may involve a more articulated inventory of information structural categories than just focus and background; I resisted the temptation of introducing any further features such as 'contrast' or 'topic', because in the absence of clear criteria to test those, they would amount to no more than arbitrary features used to trigger certain word order anomalies). More work is waiting to be done.

Accepting the conclusion drawn in the present paper, that prosody, morphosyntax and semantics are all irreducible forces in the ordering of arguments, it is worthwhile to note that all three of them pull in the same direction in the majority of cases, often masking one another; often times, definites are in the background and indefinites are focused, and if an indefinite isn't focused, that is often because it is generic and as such can be repeated. In other words, the constraints regularly converge. We could easily imagine and construct a grammar in which the prosody wants foci to follow the background (as in German), but in which, say, the background ADs, rather than the focus ADs, are mapped onto the nuclear scope. Such a grammar would produce a very different language from German, presumably one without a clear rule of thumb such as 'indefinites tend to follow definites', i.e. without convergence of the constraints.

To take another example, it seems likewise 'natural' that definiteness and animacy should converge in that sense, assuming that we speak about humans and animals more often than we do about inanimate things, and given that that which we speak about would generally be encoded as a definite. Formal grammars such as the one used in the present paper do not offer an explanation for this convergence. To the extend that such convergences are common in grammars, they perhaps hint at something like 'usability': A language (as perhaps most systems) is simply more stable and usable if little changes don't yield big effects, that is, in which principles, often redundantly, converge. This is at least a conceivable alternative to a reductionist (or 'minimalist') approach, according to which convergence must be attributed to one grammar-internal force; and, if the findings of this paper are on the right track, it is perhaps the empirically more accurate one. 


\section{References}

Büring, Daniel. 1996. Interpretation and Movement: Towards an Economy-Theoretic Treatment of German 'Mittelfeld' Word Order. Unpubl. ms. Frankfurt University.

Büring, Daniel. forthcoming. Let's Phrase It! - Focus, Word Order, and Prosodic Phrasing in German Double Object Constructions. Competition in Syntax, edited by Gereon Müller and Wolfgang Sternefeld, 101-137. Amsterdam: Benjamins.

de Hoop, Helen. 1992. Case configuration and noun phrase interpretation. Ph.D. thesis, Groningen. Published 1996 by Garland.

Diesing, Molly. 1992. Indefinites. No. 20 in Linguistic Inquiry Monograph. Cambridge, MA: MIT Press.

Eckardt, Regine. 1996. Intonation and Predication: An Investigation in the Nature of Judgement Structure. Tech. Rep. 77, SFB 340, Stuttgart \& Tübingen.

Gutiérrez-Bravo, Rodrigo. 1999. Focus, Phonological Phrasing and Word Order in Spanish and English. Unpubl. ms., UC Santa Cruz (presented at the 30th Linguistic Symposium on Romance Languages, Gainsville, FA).

Halliday, M.A.K. 1967. Notes on Transitivity and Theme. Journal of Linguistics 3:199-244.

Heim, Irene. 1982. The Semantics of Definite and Indefinite Noun Phrases. Ph.D. thesis, University of MA, Amherst.

Jackendoff, Ray S. 1997. The Architecture of the Language Faculty. Cambridge, Mass.: MIT Press.

Jacobs, Joachim. 1992. Integration. Tech. Rep. 14, SFB 282, Düsseldorf, Köln \& Wuppertal.

Kratzer, Angelika. 1995. Stage Level and Individual Level Predicates. The Generic Book, edited by Greg N. Carlson and Francis J. Pclletier, 125-175. Chicago: The University of Chicago Press.

Krifka, Manfred. 1995. Focus and the Interpretation of Generic Sentences. The Generic Book, edited by Greg N. Carlson and Francis J. Pelletier, 238-264. Chicago: The University of Chicago Press.

Krifka, Manfred. 1999. Focus, Prosody and Syntax. (part of forthcoming book on focus).

Lenerz, Jürgen. 1977. Zur Abfolge nominaler Satzglieder im Deutschen. Tübingen: Narr.

Müller, Gereon. 1998. German Word Order and Optimality Theory. Tech. Rep. 126, SFB 340, Stuttgart \& Tübingen.

Nagahara, Hiroyuki. 1994. Phonological Phrasing in Japanese. Ph.D. thesis, UCLA.

Rochemont, Michael. 1986. Focus in Generative Grammar. Amsterdam/Philadelphia: John Benjamins.

Rooth, Mats. 1996. Focus. The Handbook of Contemporary Semantic Theory, edited by Shalom Lappin, 271-297. London: Blackwell.

Schwarzschild, Roger. 1999. GIVENness, AvoidF and Other Constraints on the Placement of Accent. Natural Language Semantics 7:141-177.

Selkirk, Elisabeth. 1984. Phonology and Syntax: The Relation between Sound and Structure. Cambridge, Mass.: MIT Press.

Selkirk, Elisabeth. 1995. Sentence Prosody: Intonation, Stress, and Phrasing. The Handbook of Phonological Theory, edited by John A. Goldsmith, 550-569. London: Blackwell.

Truckenbrodt, Hubert. 1995. Phonological Phrases: Their Relation to Syntax, Focus, and Prominence. Ph.D. thesis, MIT. Published 1999 by MITWPL.

Truckenbrodt, Hubert. 1999. On the Relation between Syntactic Phrases and Phonological Phrases. Linguistic Inquiry 30:219-255.

Uechi, Akihiko. 1998. Focus Phrasing in Japanes - An Optimality Approach. Proceeding of Workshop on Focus, edited by Elena Benedicto, Maribel Romero, and Satoshi Tomioka, vol. 21 of UMass Occasional Papers in Linguistics, 259-276. Amherst, Mass.: GLSA.

Uhmann, Susanne. 1991. Fokusphonologie. Tübingen: Niemeyer.

von Stechow, Arnim. 1981. Topic, Focus, and Local Relevance. Crossing the Boundaries in Linguistics, edited by Wolfgang Klein and Willem Levelt, 95-130. Dordrecht: Reidel.

von Stechow, Arnim. 1989. Focusing and Backgrounding Operators. Tech. Rep. 6, Fachgruppe Sprachwissenschaft, Universität Konstanz.

von Stechow, Arnim. 1991. Current Issues in the Theory of Focus. Semantik - Ein internationales Handbuch der zeitgenösischen Forschung, edited by Arnim von Stechow and Dieter Wunderlich, no. 6 in HSK, 804-825. Berlin \& New York: de Gruyter.

von Stechow, Arnim, and Susanne Uhmann. 1986. Some Remarks on Focus Projection. Topic, Focus and Configurationality, edited by W. Abraham and S. de Meji, 295-320. Amsterdam: John Benjamins. 